\title{
Blocking endothelin-1-receptor/ $\beta$-catenin circuit sensitizes to chemotherapy in colorectal cancer
}

\author{
Roberta Cianfrocca', Laura Rosanò ${ }^{1}$, Piera Tocci', Rosanna Sestito ${ }^{1}$, Valentina Caprara ${ }^{1}$, Valeriana Di Castro ${ }^{1}$, Ruggero De Maria ${ }^{2}$ and \\ Anna Bagnato ${ }^{\star, 1}$
}

The limited clinical response to conventional chemotherapeutics observed in colorectal cancer (CRC) may be related to the connections between the hyperactivated $\beta$-catenin signaling and other pathways in CRC stem-like cells (CRC-SC). Here, we show the mechanistic link between the endothelin-1 (ET-1)/ET-1 receptor (ET-1R) signaling and $\beta$-catenin pathway through the specific interaction with the signal transducer $\beta$-arrestin1 ( $\beta$-arr1), which initiates signaling cascades as part of the signaling complex. Using a panel of patient-derived CRC-SC, we show that these cells secrete ET-1 and express $\mathrm{ET}_{\mathrm{A}} \mathrm{R}$ and $\beta$-arr1, and that the activation of $\mathrm{ET}_{\mathrm{A}} \mathrm{R} / \boldsymbol{\beta}$-arr1 axis promotes the cross-talk with $\beta$-catenin signaling to sustain stemness, epithelial-to-mesenchymal transition (EMT) phenotype and response to chemotherapy. Upon $\mathrm{ET}_{\mathrm{A}} \mathrm{R}$ activation, $\beta$-arr1 acts as a transcription co-activator that binds $\beta$-catenin, thereby promoting nuclear complex with $\beta$-catenin/TFC4 and $\mathrm{p} 300$ and histone acetylation, inducing chromatin reorganization on target genes, such as ET-1. The enhanced transcription of ET-1 increases the self-sustained ET-1/ $\beta$-catenin network. All these findings provide a strong rationale for targeting ET-1R to hamper downstream $\beta$-catenin/ET-1 autocrine circuit. Interestingly, treatment with macitentan, a dual $\mathrm{ET}_{\mathrm{A}} \mathrm{R}$ and $\mathrm{ET}_{\mathrm{B}} \mathrm{R}$ antagonist, able to interfere with tumor and microenvironment, disrupts the ET-1R/ $\beta$-arr1- $\beta$-catenin interaction impairing pathways involved in cell survival, EMT, invasion, and enhancing sensitivity to oxaliplatin (OX) and 5-fluorouracil (5-FU). In CRC-SC xenografts, the combination of macitentan and OX or 5-FU enhances the therapeutic effects of cytotoxic drugs. Together, these results provide mechanistic insight into how ET-1R coopts $\beta$-catenin signaling and offer a novel therapeutic strategy to manage CRC based on the combination of macitentan and chemotherapy that might benefit patients whose tumors show high $\mathrm{ET}_{\mathrm{A}} \mathrm{R}$ and $\beta$-catenin expression.

Cell Death and Differentiation (2017) 24, 1811-1820; doi:10.1038/cdd.2017.121; published online 14 July 2017

Colorectal cancer (CRC) is one of the main causes of tumorrelated mortality worldwide and its therapy mainly relies on the use of conventional chemotherapeutic drugs. ${ }^{1}$ Most CRC carry mutations leading to overactivation of the $\beta$-catenin pathway. ${ }^{2} \mathrm{CRC}$ stem-like cells (CRC-SC) have been shown to be responsible for tumor propagation, metastasis and resistance to conventional anticancer drugs. ${ }^{3-10}$ An accurate understanding of the cross-talk between signaling in CRC-SC could allow the development and the clinical use of effective therapies to enhance CRC drug sensitivity. In CRC-SC $\beta$-catenin signaling pathway promotes tumor growth, and progression by sustaining stem cell expansion. ${ }^{11-14} \mathrm{~A}$ key property of CRC-SC with activated $\beta$-catenin signaling is the protection against conventional chemotherapeutics. ${ }^{2,15}$ The molecular mechanisms responsible of the fine-tuning of $\beta$-catenin-mediated stemness and drug response remain largely unexplored but represent a potentially promising area for novel therapeutic interventions. Therefore, drugging upstream signaling molecules endowed with functions that regulate $\beta$-catenin activity may represent a novel approach to sensitize to chemotherapy. In this context, endothelin-1 (ET-1) elicits pleiotropic effects in tumor cells and in the host microenvironment, modulating the epithelial-to-mesenchymal transition (EMT), the expansion of vascular network and immune response. ${ }^{16} \mathrm{ET}-1$ acts through autocrine and paracrine signaling by binding two distinct receptors: endothelin $\mathrm{A}$ $\left(E T_{A} R\right)$ and $B\left(E T_{B} R\right)$, which belong to the G-protein-coupled receptor family. The activation of $E T-1 / E_{A} R$ axis is recognized as a common mechanism underlying the progression of various solid tumors, including CRC. ${ }^{16-18}$ In CRC, the components of the ET-1 system are expressed not only by tumor cells, but also by microenvironmental elements, such as fibroblasts, endothelial cells and macrophages. ${ }^{17-26}$ Increased levels of ET-1 have been detected in plasma and tissue samples from patients with CRC. ${ }^{19,20}$ Moreover, in CRC the ET-1 gene regulation is directly upregulated by $\beta$-catenin. ${ }^{27}$ Microarray molecular profiling and real-time PCR on $\mathrm{CD} 133^{+}$ fractions of $C R C$ lines revealed that ET-1 transcripts are highly expressed compared with $\mathrm{CD} 133^{-}$counterparts. ${ }^{28} \mathrm{~A}$ preclinical study in CRC demonstrated that zibotentan, a selective $E T_{A} R$ antagonist, suppressed tumor growth and progression indicating a potential role of this antagonist as adjuvant therapy. ${ }^{29}$ More recently in CRC cells, it has been demonstrated that overexpression of the ET-1 gene is a determinant of acquired resistance to MEK and PI3K inhibitors. ${ }^{30}$ However

\footnotetext{
${ }^{1}$ Preclinical Models and New Therapeutic Agents Unit, Regina Elena National Cancer Institute, Rome, Italy and ${ }^{2}$ Institute of General Pathology, Catholic University, Rome, Italy

${ }^{*}$ Corresponding author: A Bagnato, Preclinical Models and New Therapeutic Agents Unit, Regina Elena National Cancer Institute, Via Elio Chianesi, 53, Rome 00144, Italy. Tel: +39 065266 5618; Fax: +39 065266 2600; E-mail: annateresa.bagnato@ifo.gov.it

Received 20.3.17; revised 09.6.17; accepted 23.6.17; Edited by G Kroemer; published online 14.7.17
} 
the molecular mechanism of ET-1 axis to protect against drugs treatment in CRC remains elusive.

In our recent studies, we reported that $E T-1 / E T_{A} R$ axis, through the contribution of the scaffold protein $\beta$-arrestin1 $(\beta$-arr1), appears to be critical in the signaling cross-talk, providing a mechanism of escape to a new less-adverse niche, in which evasion of drug-induced apoptosis ensures cell survival required for tumor progression. ${ }^{16,31-35}$ In this regard, ET-1 has been recently identified as a key component that sustains maintenance and clonal expansion of cardiovascular stem cells population. ${ }^{36}$ Moreover, a recent report suggests that $\beta$-arr1 has an important protective role, reducing the chemotherapy-induced intestinal stem cell apoptosis. ${ }^{37}$ To dissect the intricate interplay between $E T-1 R / \beta$-arr1 and $\beta$-catenin, here we report a ET-1R/ $\beta$-arr1-mediated epigenetic mechanism in regulating $\beta$-catenin signaling to promote EMT and protection against chemotherapy. Understanding whether targeting $\mathrm{ET}-1 \mathrm{R} / \beta$-arr1 connected with $\beta$-catenin pathway in CRC-SC can restore sensitivity to chemotherapy, is thus essential to develop more effective strategies in this malignancy.

\section{Results}

Expression of ET-1R/ $\boldsymbol{\beta}$-arr1 axis in CRC-SC. We first evaluated the expression of ET-1 axis in CRC-SC features, by using a panel of patient-derived CRC-SC isolated from human tumor samples (CC09, CSC5, CSC2 and CSC1), all carrying APC gene mutations. ${ }^{3,10,12}$ The mRNA and protein expression analysis showed that all CRC-SC expressed ET-1 and its receptors, $E T_{A} R$ and $E T_{B} R$, and released high levels of ET-1, within the physiologically range needed for the activation of ET-1R in an autocrine manner ${ }^{38}$ (Figures $1 \mathrm{a}-\mathrm{C}$ ). To explore the role of $\beta$-arr1 to create intracellular signaling cross-talk upon ET-1R activation, we first evaluated $\beta$-arr1 expression in CRC-SC. These cells expressed $\beta$-arr1 both at mRNA and protein levels (Figures $1 a$ and b). After ET-1 stimulation, we observed an increase of CRC-SC viability, which was reduced after treatment with macitentan, a potent $E T_{A} R$ antagonist with significant affinity for $E T_{B} R$. The same effect was observed after $\beta$-arr1 silencing (Figure 1d and Supplementary Figure S1a and S2). When cultured in stem cell medium, CRC-SC grow in large round, unattached floating spheroid colonies (sphere). As shown in Figure 1e, whereas the ET-1 addition enhanced the CRC-SC sphere formation ability, increasing not only the sphere number but also the size, macitentan treatment negatively affected the stemness property of $\mathrm{CRC}-\mathrm{SC}$, indicating that the $\mathrm{ET}-1 \mathrm{R} / \beta$ arr1 axis sustains CRC-SC features.

ET-1R/ $\beta$-arr1-driven EMT and invasive behavior in CRC-SC. Next, we analyzed whether the features of CRC-SC driven by $\mathrm{ET}_{\mathrm{A}} \mathrm{R} / \beta$-arr 1 were associated with molecular changes consistent with EMT. ${ }^{39-44}$ To this end we examined the expression of the epithelial marker E-cadherin and its transcriptional repressors, Twist and Snail, as well as the expression of mesenchymal markers, such as $\mathrm{N}$-cadherin and vimentin. Upon ET-1 stimulus, we observed an increase of $\mathrm{N}$-cadherin, vimentin, Snail and Twist expression levels, associated with a concomitant decrease in $\mathrm{E}$-cadherin expression (Figures $2 \mathrm{a}$ and $\mathrm{b}$ ). In addition, as a result of macitentan treatment or $\beta$-arr1 silencing, restored E-cadherin expression and inhibited $\mathrm{N}$-cadherin, Snail and Twist expression were observed (Figure 2b). Concordantly, the analysis of mRNA levels upon ET-1 stimulation showed the increased expression levels of Snail and $\mathrm{N}$-cadherin and the decrease of E-cadherin that were reverted following macitentan treatment (Figure 2c). Remarkably, macitentan, or the $\beta$-arr1 knockdown, inhibited the ET-1-induced suppression of E-cadherin promoter activity (Figure $2 \mathrm{~d}$ ) and induction of Snail promoter activity (Figure 2e). Next, we evaluated whether the $E T_{A} R / \beta$-arr1-driven acquisition of EMT phenotype correlates with expression and activation of the proteolytic enzymes, matrix metalloproteases (MMP), and with an increase of invasive potential of CRC-SC. As shown in Figures $2 f$ and $g$, the ET-1-induced MMP-2 and -9 secretion and activation were inhibited by macitentan treatment, as well as $\beta$-arr1 silencing, as determined by immunoblotting and zymography. In this context, as a result of enhanced proteolitic activity of CRC-SC upon $E T_{A} R / \beta$-arr1 signaling activation, when CRC-SC were silenced for $\beta$-arr1 or were treated with macitentan, the ET-1-induced cell invasion was significantly impaired compared with control cells (Figure $2 \mathrm{~h}$ ), providing evidence that $\mathrm{ET}_{\mathrm{A}} \mathrm{R} / \beta$-arr1 axis activation may be $\mathrm{a}$ critical event to drive EMT and invasive behavior in CRC-SC.

ET-1R/ $\beta$-arr1 axis links $\beta$-catenin pathway in CRCSC. The $\beta$-catenin signaling pathway represents an hallmark of CRC-SC governing the maintenance of stemness. ${ }^{2,11-15}$ We observed that ET-1 stimulation induced the $\beta$-catenin nuclear translocation, an effect that was inhibited upon macitentan treatment (Figure 3a), enhancing the levels of serine/threonine non-phosphorylated $\beta$-catenin active form (Supplementary Figure S3a). We analyzed the nucleocytoplasmic shuttling of both $\beta$-arr1 and $\beta$-catenin in the cytosolic and nuclear extracts of CRC-SC upon different times of ET-1 stimulation. ET-1 induced a time-dependent nuclear translocation of both proteins with a peak after 30 and 60 min of ET-1 challenge (Figure $3 b$ ). Of relevance, this effect was strongly reduced upon macitentan treatment and $\beta$-arr1 silencing (Figure $3 c$ ). Moreover, we analyzed $\beta$-arr1 and $\beta$-catenin potential physical interaction in the nucleus, by using coimmunoprecipitation (IP) assays. $\beta$-arr1 bound to $\beta$-catenin in the nuclei of ET-1-treated cells (Figure $3 d$ ), and this interaction was inhibited by macitentan, suggesting that $\mathrm{ET}-1 \mathrm{R} / \beta$-arr1 links $\beta$-catenin in the nucleus of CRC-SC that is hampered by ET-1R blockade. Consistent with these results, the transcriptional activity of $\beta$-catenin, induced by ET-1 in CRC-SC, was inhibited after treatment with macitentan, or by $\beta$-arr1 silencing (Figure $3 e$ and Supplementary Figure $\mathrm{S} 3 \mathrm{~b}$ ), indicating that $\mathrm{ET}-1 / \beta$-arr $1 / \beta$-catenin interaction is necessary for inducing $\beta$-catenin/T cell factor 4 (TCF4) transcriptional activity. Given that ET-1 is also a downstream target gene of $\beta$-catenin/TCF $4,{ }^{27,31,32}$ by using a reporter plasmid with $\mathrm{ET}-1$ promoter sequence, containing a functional TCF binding element (TBE), we demonstrated that ET-1 promoter activity was significantly upregulated after ET-1 stimulation and inhibited when the cells were treated with macitentan, or silenced for $\beta$-arr1 (Figure 3f). Next, through 
a

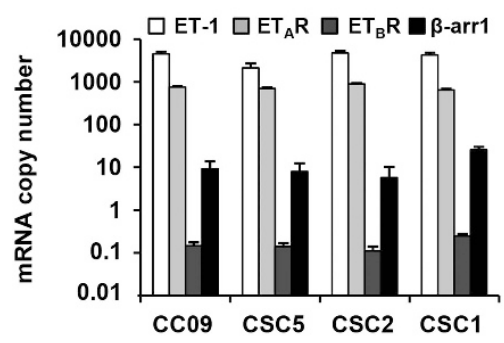

d

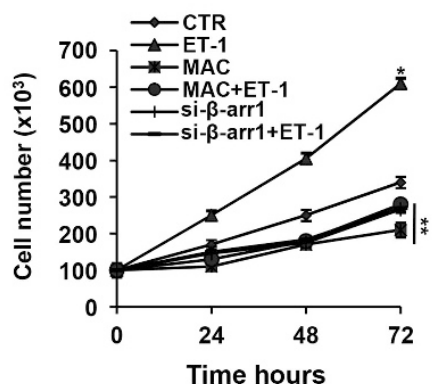

b

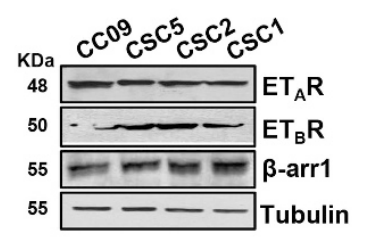

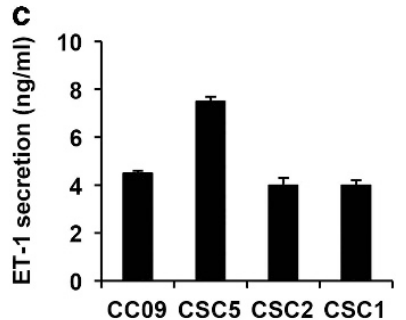
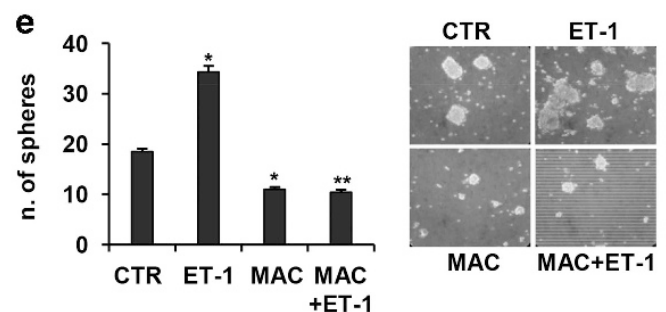

Figure 1 Expression of ET-1/ $\beta$-arr1 axis in CRC-SC. (a) In a panel of patient-derived CRC-SC (CC09, CSC5, CSC2 and CSC1), expression of ET-1, $\mathrm{ET}_{\mathrm{A}} \mathrm{R}, \mathrm{ET}_{\mathrm{B}} \mathrm{R}$ and $\beta$-arr1 mRNA copy number was analyzed by real-time PCR (qPCR) normalized using endogenous cyclophilin-A. Values are shown as mean \pm S.D. from three independent experiments repeated in triplicates. (b) $E T_{A} R, E T_{B} R$ and $\beta$-arr1 protein expression was analyzed by immunoblotting (IB). Tubulin was used as loading control. (c) $E T-1$ secretion evaluated by ELISA in $24 \mathrm{~h}$ cell-conditioned media. Values are shown as mean \pm S.D. from three independent experiments repeated in triplicates. (d) Time-dependent effect of treatment with ET-1 $(100 \mathrm{nM})$ and/or macitentan (MAC) $(1 \mu \mathrm{M})$ on cell growth of CC09 cells transfected with siRNA negative control (SCR) or with $\beta$-arr1 siRNA (si- $\beta$-arr1). Values are shown as mean \pm S.D. from three independent experiments repeated in triplicates ( ${ }^{*} P<0.001$ versus $C T R ;{ }^{* *} P<0.001$ versus ET-1) (e) Sphere formation assay of CSC5 cells, treated with ET-1 $(100 \mathrm{nM})$ and MAC $(1 \mu \mathrm{M})$ alone or in combination for 7 days. Values are shown as mean \pm S.D. from three independent experiments repeated in triplicates $\left({ }^{\star} P<0.05\right.$ versus $\mathrm{CTR} ;{ }^{\star \star} P<0.05$ versus $\left.\mathrm{ET}-1\right)$. Representative images of tumor spheres were shown in the right panel

chromatin immunoprecipitation (ChIP) assays, we demonstrated that in CRC-SC, both $\beta$-arr1 and $\beta$-catenin, together with TCF4, were recruited on TBE of ET-1 promoter. In parallel, ET-1 stimulation induced the acetylation of histone 3 at Lysine 27 (H3K27), and the competent recruitment of p300 together with $\beta$-arr1 and $\beta$-catenin (Figures $3 g$ and $h$ ). Knocking down of $\beta$-arr1 or treatment with macitentan abolished the ET-1-induced effect (Figures $3 g$ and $h$ ). Hence, in response to ET-1R activation, $\beta$-arr1 was selectively enriched with $\beta$-catenin on ET-1 promoter and the cooperation between these two proteins enhanced the autoregulatory $\beta$-catenin-mediated transcription of ET-1 gene. In parallel, we evaluated the influence of the ET-1 axis activation on the transcription of a set of specific $\beta$-catenin/TCF4-target genes, such as ET-1, Cyclin D1 and Axin 2. As shown in Figure 3i, the analysis of mRNA showed an upregulation of the levels of these genes upon ET-1 stimulation, and a considerable decrease after macitentan treatment. Collectively, our findings highlight the role of $\mathrm{ET}-1 \mathrm{R} / \beta$-arr1 signaling to interconnect the $\beta$-catenin pathway in CRC-SC, to form specific nuclear complex that regulates hystone acetylation in specific cromosomal regions, upregulating the transcription of different $\beta$-catenin target genes, including the self-sustained ET-1/ $\beta$-catenin activity, as a magnifying mechanism.

ET-1R blockade sensitizes CRC-SC to standard chemotherapeutic drugs. In CRC-SC, ET-1R/ $\beta$-arr1 modulates cell survival pathways. Thus, the stimulation of CRC-SC with ET-1 was accompanied with phosphorylation of both p42/
p44MAPK and Akt, and macitentan treatment, or the specific $\beta$-arr1 silencing, significantly decreased the ET-1-mediated MAPK and Akt activation (Figure $4 a$ and Supplementary Figure S4a). Because a typical property of CRC-SC is the resistance to treatment with standard chemotherapeutic agents, as oxaliplatin (OX) and 5-fluorouracil (5-FU), we evaluated the response of CRC-SC following exposure to OX and 5-FU at clinically relevant doses, ${ }^{10}$ and found that these cells were poorly responsive to chemotherapeutic drugsinduced apoptosis even at the highest concentration used (Figure 4b). The treatment with macitentan or the loss of $\beta$-arr1 in a combination regimen with $\mathrm{OX}$ or $5-\mathrm{FU}$, induced a more effective reduction of cell vitality (Figure $4 \mathrm{C}$ and Supplementary Figure S4b). Furthermore, CRC-SC that overexpressed exogenous $\beta$-arr1-FLAG showed a greater poor sensitivity to OX or $5-\mathrm{FU}$, compared with parental cells (Figure $4 d$ and Supplementary Figure S1b), suggesting that $\mathrm{ET}_{\mathrm{A}} \mathrm{R} / \beta$-arr1 blockade might sensitize $\mathrm{CRC}$-SC to $\mathrm{OX}$ and 5-FU-induced apoptosis. Mechanistically, we found that the combined treatment of macitentan with chemotherapeutic agents, resulted in an enhanced expression of the poly ADP-ribose polimerase (PARP) cleaved form (Figure $4 \mathrm{e}$ and Supplementary Figure S4c). In addition, we found that ET-1 increased the expression of the prosurvival factor $\mathrm{Bcl}-\mathrm{XL}$, which was strongly reduced upon macitentan and $\mathrm{OX}$ co-treatment (Figure 4f). This implies that the activation of $\mathrm{ET}-1 \mathrm{R} / \beta$-arr1 survival signaling is involved in the protection of CRC-SC against chemotherapeutics, suggesting that 


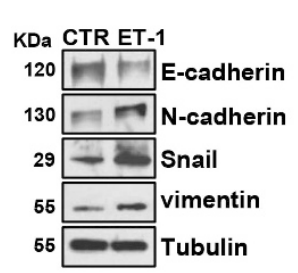

b

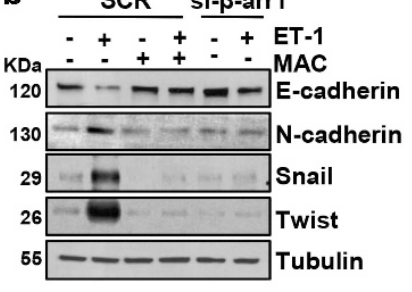

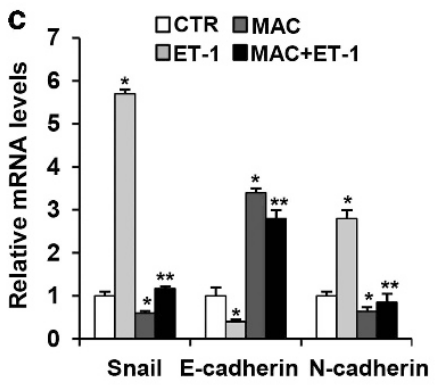

Snail E-cadherin $\mathrm{N}$-cadherin
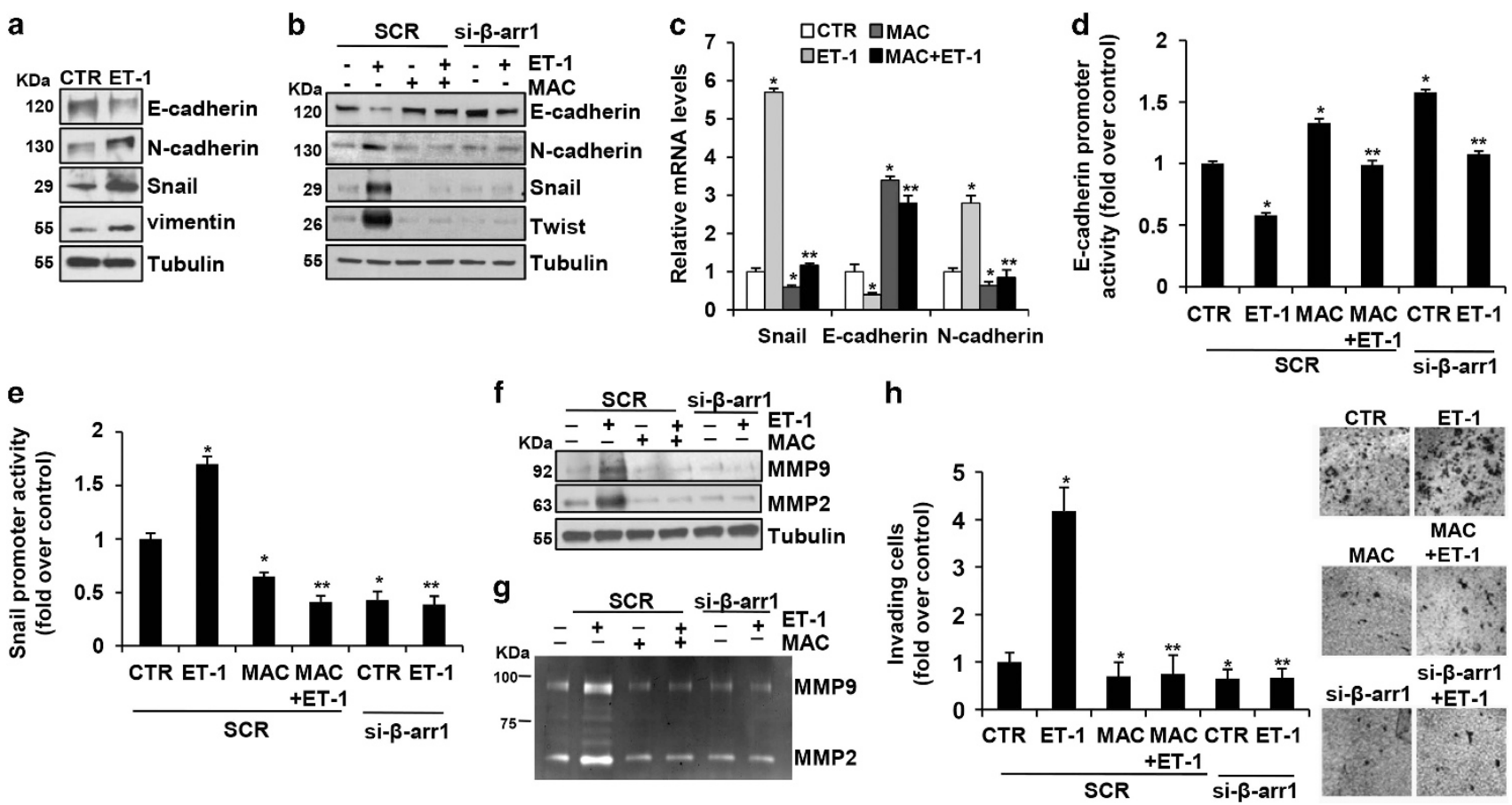

Figure $2 \mathrm{ET}$-1R/ $\beta$-arr1 axis drives EMT process in CRC-SC. (a) Lysates from CC09 cells were analyzed by IB for the expression of epithelial (E-cadherin) and mesenchymal ( $\mathrm{N}$-cadherin, Snail, and vimentin) markers after ET-1 (100 nM) stimulation for $24 \mathrm{~h}$. Tubulin was used as loading control. (b) Lysates from CC09 cells transfected with SCR or si- $\beta$ arr1 and treated for $24 \mathrm{~h}$ with ET-1 $(100 \mathrm{nM})$ and/or MAC $(1 \mu \mathrm{M})$ were analyzed by IB for the expression of E-cadherin, N-cadherin Snail and Twist. Tubulin was used as loading control. (c) Snail, E-cadherin, and N-cadherin expression in CC09 cells upon ET-1 (100 nM) and/or MAC $(1 \mu \mathrm{M})$ treatment evaluated by qPCR, normalized using endogenous cyclophilin-A. Values are shown as mean \pm S.D. from three independent experiments repeated in triplicates $\left({ }^{*} P<0.002\right.$ versus CTR; ${ }^{* *} P<0.005$ versus ET-1). (d) E-cadherin promoter activity and Snail promoter activity (e) evaluated in CC09 cells transfected with SCR or si- $\beta$-arr1 and treated for $24 \mathrm{~h}$ with ET-1(100 nM) and/or MAC (1 $\mu \mathrm{M})$. Values are shown as mean \pm S.D. from three independent experiments repeated in triplicates $\left({ }^{\star} P<0.01\right.$ versus $C T R ;{ }^{\star \star} P<0.001$ versus ET-1 in SCR-transfected cells). (f) Lysates from CC09 cells transfected with SCR or si- $\beta$-arr1 treated with ET-1 (100 nM) and/or MAC $(1 \mu \mathrm{M})$ for $24 \mathrm{~h}$ were analyzed for MMP-2 and -9 by IB. Tubulin was used as loading control. (g) Conditioned media collected from CCO9 treated as in (f) were used to determine the secretion and activity of MMP-2 and -9 by gelatin zymography. (h) Cell invasion assay of CC09 cells transfected with SCR or si- $\beta$-arr1 and exposed to ET-1 (100 nM) and/or MAC $(1 \mu \mathrm{M})$ for $24 \mathrm{~h}$. Values are shown as mean \pm S.D. from three independent experiments repeated in triplicates ( ${ }^{*} P<0.002$ versus $C T R ;{ }^{*} P<0.001$ versus $E T-1$ in SCR-transfected cells). Representative images of invading cells were shown in the right panel

molecular targeting of ET-1R in CRC-SC might improve the efficacy of chemotherapeutic regimens.

ET-1R blockade inhibits tumor growth and restores sensitivity to chemotherapy in CRC-SC patient-derived xenografts. To verify whether ET-1R blockade by macitentan would also affect tumor growth in vivo, patient-derived CC09 and CSC5 CRC-SC were injected into the flank of mice and were allowed to grow until they reached a detectable size. The xenografts obtained were confirmed as colorectal adenocarcinoma, as showed by hematoxylin-eosin staining in the representative sections from tumor xenografts (Figure $5 \mathrm{a}$ and Supplementary Figure S5a). Next, we tested the effect of macitentan alone or in combination with chemotherapy in CRC$\mathrm{SC}$ xenografts. After the appearance of palpable tumors (day 14 for CC09 xenografts, and day 42 for CSC5 xenografts), mice were randomized into different groups of ten mice undergoing the following treatments for 4 weeks: (i) vehicle (control), (ii) macitentan (30 mg/Kg/oral daily), (iii) OX $(0.25 \mathrm{mg} / \mathrm{Kg} / \mathrm{i} . p$. once a week) or 5 -FU (15 mg/Kg/i.p daily), (iv) macitentan plus OX or 5-FU. These treatments, were generally well tolerated without any loss of weight or detectable signs of acute or delayed toxicity. At the end of 4 weeks of treatment, tumor size of mice treated with macitentan significantly decreased compared with vehicle-treated mice $(\sim 60 \%$ for CC09 xenografts; $55 \%$ for CSC5 xenografts, $P<0.02$ ), demonstrating the therapeutic potential of macitentan in controlling tumor growth. Most importantly, a synergistic growth-inhibitory effect, as calculated by Chou and Talalay method, was observed when macitentan was used in combination with OX, compared with macitentanor OX-treated mice (90 versus $68 \%$ or $12 \%$ respectively, for CC09; 84 versus $55 \%$ or $49 \%$ respectively, for CSC5 xenografts; $P<0.05)$ or in combination with 5 -FU compared with macitentan- or 5-FU-treated mice (91 versus $50 \%$ or $10 \%$ respectively, for CC09 xenografts; $P<0.05$, Figure 6), thus proving the ability of macitentan to sensitize CRC-SC xenografts to different chemotherapeutic drugs. Moreover, the therapeutic effects of macitentan were long-lasting, both in monotherapy or combination with chemotherapeutic drugs, for up to $2 / 3$ weeks after termination of treatments. Indeed, we still found a persisted tumor growth reduction even during the treatment-free period in mice treated with macitentan compared with vehicle-treated mice $(46 \%$ at day 63 , for CC09 xenografts, Figure $5 \mathrm{a} ; 40 \%$ at day 55 for CC09 xenografts, Figure 6; 61\% at day 77 for CSC5 xenografts, Supplementary Figure S5a; $P<0.02$ ), and a persistent synergistic inhibitory effect in combinatorial regimes (91 versus $46 \%$ for macitentan or $37 \%$ for OX, for CC09 xenografts; 89 versus $40 \%$ for 


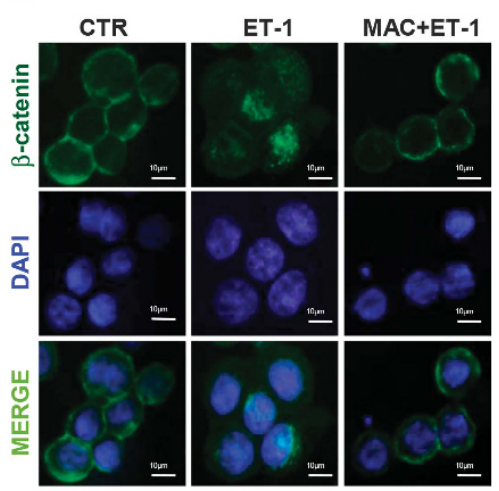

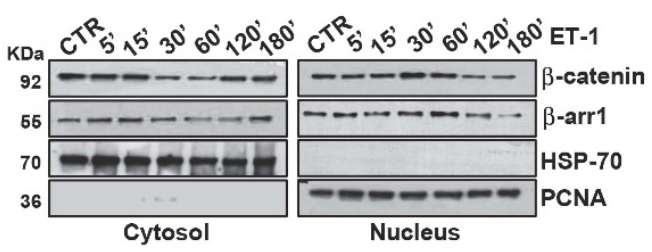

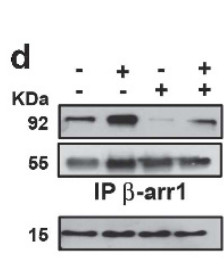

e

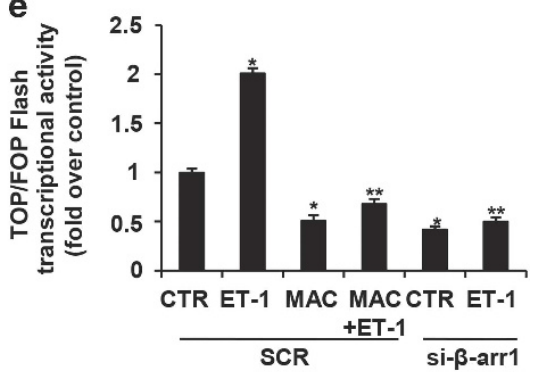

C

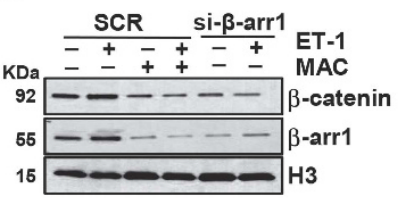

$5+\quad+\quad+$ ET-1

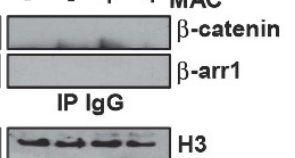

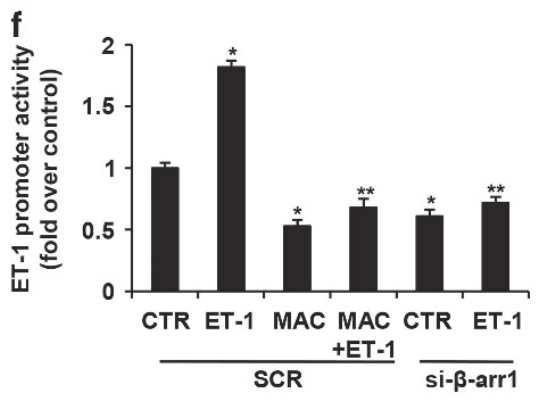

g

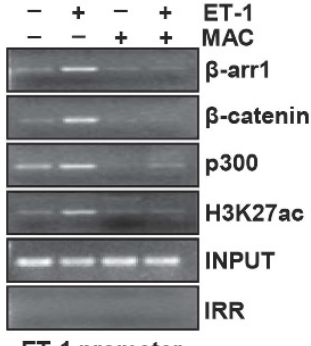

h

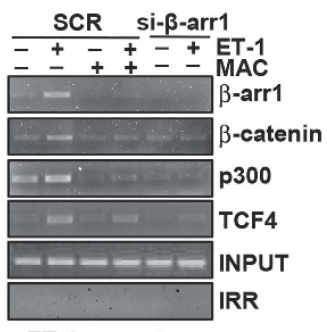

ET-1 promoter

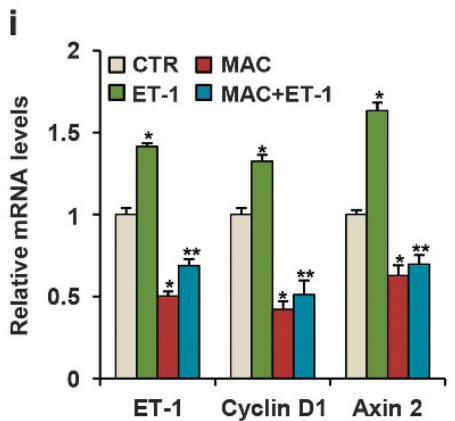

Figure $3 \mathrm{ET}-1 \mathrm{R} / \beta$-arr1 axis induces $\beta$-catenin pathway in CRC-SC. (a) $\beta$-catenin localization evaluated by immunofluorescence staining (green) in CC09 cells stimulated for 30 min with ET-1 $(100 \mathrm{nM})$ alone or in combination with MAC $(1 \mu \mathrm{M})$. Nuclei were counterstained with DAPI (blue) (scale bar, $10 \mu \mathrm{m})$. (b) IB analysis for $\beta$-catenin and $\beta$-arr1 protein expression in cytoplasmic and nuclear extract of CC09 cells treated with ET-1(100 nM) for the indicated times. HSP-70 and PCNA were used as cytoplasmic and nuclear loading control, respectively. (c) IB analysis for $\beta$-catenin and $\beta$-arr1 protein expression in nuclear extracts of CC09 cells transfected with SCR or si- $\beta$-arr1 and treated for 30 min with ET-1 $(100 \mathrm{nM})$ and/or MAC $(1 \mu \mathrm{M})$. Histone H3 (H3) was used as loading control. (d) Nuclear extracts of CC09 cells, treated for $30 \mathrm{~min}$ with ET-1 (100 nM) and/or MAC $(1 \mu \mathrm{M})$, were immunoprecipitated (IP) with anti- $\beta$-arr1 or with irrelevant $\operatorname{lgG}(\mathrm{IgG})$ and immunoblotted with anti- $\beta$-catenin and anti- $\beta$-arr1. $\mathrm{H} 3$ was used as loading control. (e) $\beta$-catenin transcriptional activity evaluated in CC09 cells transfected with SCR or si- $\beta$-arr1 and treated for $24 \mathrm{~h}$ with ET-1 (100 nM) and/or MAC ( $1 \mu \mathrm{M})$. Values are shown as mean \pm S.D. from three independent experiments repeated in triplicates ( ${ }^{*} P<0.001$ versus $C T R ;{ }^{* \star} P<0.002$ versus ET-1 in SCR-transfected cells). (f) ET-1 promoter activity evaluated in CC09 cells treated as in (e). Values are shown as mean \pm S.D. from three independent experiments repeated in triplicates $\left({ }^{*} P<0.001\right.$ versus CTR; ${ }^{* *} P<0.001$ versus ET-1 in SCR-transfected cells). ChIP analysis performed in CC09 cells treated for 30 min with ET-1 (100 nM) and/or MAC (1 $\mu$ M) (g) or in CC09 cells transfected with SCR or si- $\beta$-arr1 and treated for 30 min with ET-1 $(100 \mathrm{nM})$ and/or MAC $(1 \mu \mathrm{M})(\mathbf{h})$. Chromatin was incubated with $\beta$-arr1, $\beta$-catenin, p300, H3K27ac and TCF4 Abs and analyzed by $\mathrm{PCR}$ analysis by using specific primers for ET-1 promoter. Non-specific immunoglobulin $\mathrm{G}(\mathrm{lgG})$ was used as irrelevant $\mathrm{Ab}$ (IRR). The input DNA lane represents one-twentieth of the precleared chromatin used in each ChIP reaction. (i) ET-1, Cyclin D1 and Axin 2 mRNA expression in CC09 cells stimulated for $24 \mathrm{~h}$ with ET-1 (100 nM) alone or in combination with MAC $(1 \mu \mathrm{M})$ evaluated by qPCR, normalized using endogenous cyclophilin-A. Values are shown as mean \pm S.D. from three independent experiments repeated in triplicates $\left({ }^{*} P<0.01\right.$ versus $\mathrm{CTR} ;{ }^{* *} P<0.05$ versus $\left.\mathrm{ET}-1\right)$

macitentan or $20 \%$ for 5 -FU, for CC09 xenografts, and 83 versus $61 \%$ for macitentan or $57 \%$ for OX, for CSC5 xenografts; $P<0.05)$. In parallel, immunoblotting analysis of tumor xenografts of mice co-treated with macitentan and OX showed a marked effect in reducing MAPK and Akt activation, and a reversion of EMT effectors compared with controls (Figures 5b and c and Supplementary Figures S5b and c). These findings indicate that blockade of ET-1R with macitentan, in combination with chemotherapeutic drugs, controls EMT aggressive phenotype of CRC-SC, thus increasing sensitivity to the chemotherapy and promoting tumor regression.

\section{Discussion}

The presence of stem cell-like cells has been recognized as the main cause of failure in the treatment of several malignancies. $^{5,6}$ It is therefore evident that a therapeutic approach to target CSC pool could be more effective to eradicate tumor. Drug sensitivity is frequently associated with dysregulation of a signaling network rather than of a single pathway. In the present study, we provide evidence that ET-1R/ $\beta$-arr1 links $\beta$-catenin signaling to sustain CRC-SC features, also through the amplification of ET-1 autocrine loop, outlining a model in which ET-1 interlinks $\beta$-catenin signaling to support progression and recurrence of $\mathrm{CRC}$. The findings presented here reveal that $E T-1 R / \beta$-arr1 axis has a critical role in $C R C$ SC signaling and chemoprotection. Notably, ET-1R blockade by macitentan markedly affected the signaling cross-talk mediated by $\beta$-arr1 involved in the maintenance of CRC-SC and drug response. Specifically, ET-1R blockade results in a strong decrease of survival Akt/MAPK signaling pathways, ${ }^{45,46}$ with the consequent reduction of cell growth 
a
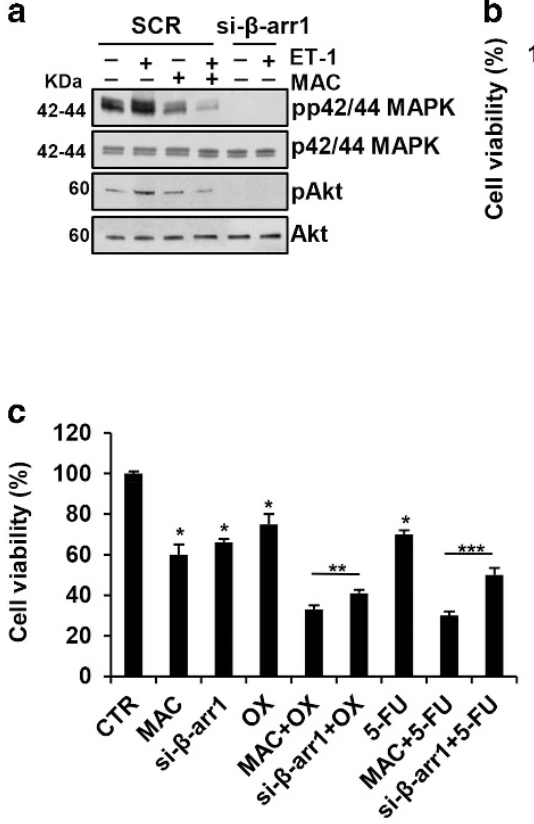
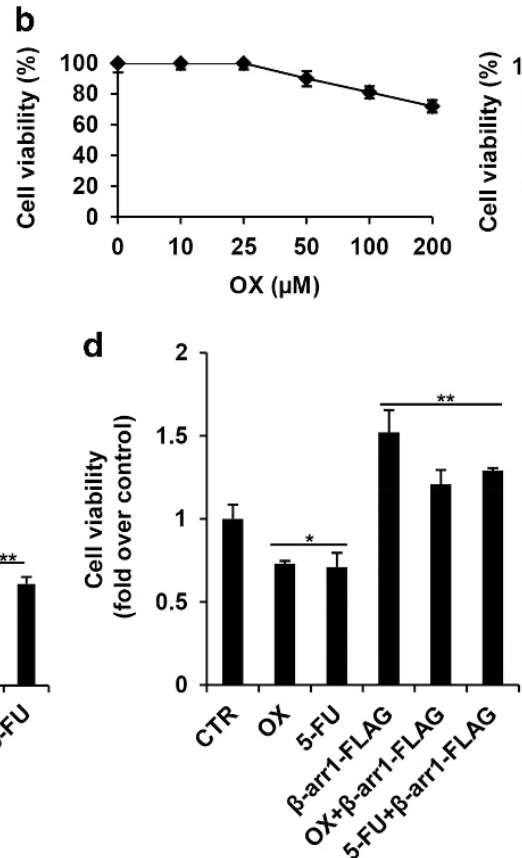

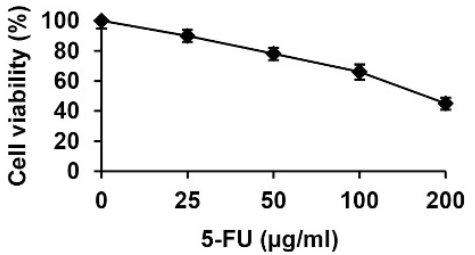

e
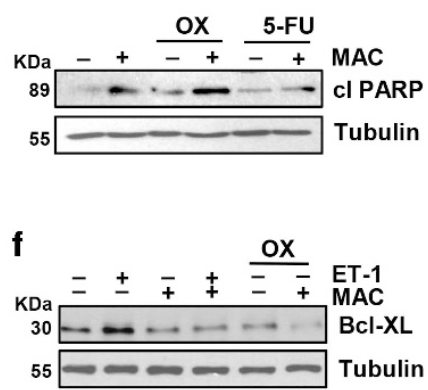

Figure 4 ET-1R blockade sensitizes CRC-SC to standard chemotherapeutic drugs. (a) Lysates from CC09 cells treated for $1 \mathrm{~h}$ with ET-1 (100 nM) and/or MAC (1 $\mu \mathrm{M})$ and transfected with SCR or with si- $\beta$-arr1 were immunoblotted with anti-pp42/44MAPK, anti-p42/44MAPK, anti-pAkt and anti-Akt. (b) Effect of exposure to different concentrations of oxaliplatin (OX) and 5-fluorouracil (5-FU) after 24 h on cell vitality of CC09 cells. (c) Time-dependent effect of treatment with MAC (1 $\mu \mathrm{M})$ or OX (100 $\mu \mathrm{M})$ or 5-FU (50 $\mu \mathrm{g} / \mathrm{ml})$ alone and combination, for $24 \mathrm{~h}$ on cell growth of CC09 cells transfected with SCR or with si- $\beta$-arr1. Values are shown as mean \pm S.D. from three independent experiments repeated in triplicates ( ${ }^{*} P<0.001$ versus CTR; ${ }^{* *} P<0.001$ versus $\mathrm{OX} ;{ }^{* *} P<0.002$ versus 5 -FU). (d) Effect of treatment with $\mathrm{OX}(100 \mu \mathrm{M})$ or 5 -FU (50 $\left.\mu \mathrm{g} / \mathrm{ml}\right)$, for $24 \mathrm{~h}$ on cell growth of CC09 cells transfected with empty vector (Mock) or with $\beta$-arr1-FLAG. Values are shown as mean \pm S.D. from three independent experiments repeated in triplicates $\left({ }^{\star} P<0.002\right.$ versus CTR; ** $P<0.002$ versus chemotherapy-treated cells). (e) IB analysis of PARP cleaved form (cl PARP) in CC09 cells treated for $24 \mathrm{~h}$ with MAC (1 $\mu \mathrm{M})$ or OX (100 $\mu \mathrm{M})$ or 5 FU $(50 \mu \mathrm{g} / \mathrm{ml})$ alone and combination. Tubulin was used as loading control. (f) IB analysis of Bcl-XL in CCO9 cells treated for $24 \mathrm{~h}$ with ET-1 (100 nM) or MAC (1 $\mu \mathrm{M})$ or OX $(100 \mu \mathrm{M})$ alone and combination. Tubulin was used as loading control

a
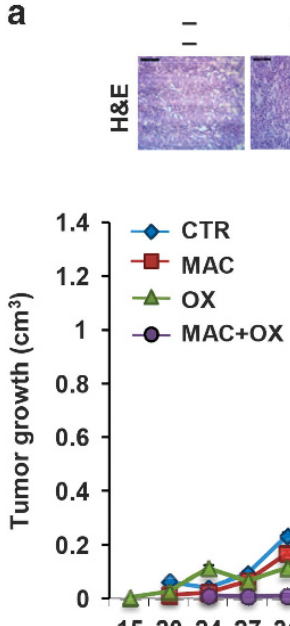

1520242731343841454852555963

Days after tumor injection b

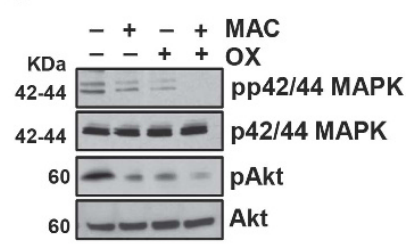

c

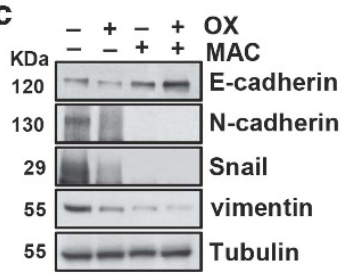

Figure 5 ET-1R blockade by macitentan inhibits tumor growth and restores sensitivity to oxaliplatin in CRC-SC xenografts. (a) CC09 cells $\left(5 \times 10^{5}\right)$ were injected s.c. into the flank of nude mice. When tumors were detected, mice were treated with vehicle (CTR), or MAC (30 mg/Kg/oral daily), or OX (0.25 mg/Kg/i.p. once a week), or MAC (30 mg/Kg/ oral daily) with OX ( $0.25 \mathrm{mg} / \mathrm{Kg} / \mathrm{i}$.p. once a week) combination for 4 weeks. The comparison of the time course of tumor growth curves by two-way ANOVA with group-by-time interaction for tumor growth was statistically significant $(P<0.02)$. Data points, averages \pm S.D. The upper panels represented the hematoxylin-eosin staining of transplanted tumor xenografts (scale bar, $50 \mu \mathrm{m}$ ) or the images of tumors from each treatment group. (b) Expression of pp42/44MAPK, p42/44MAPK, pAkt and Akt as evaluated by IB on total extracts from tumors of CC09 xenografts. (c) E-cadherin, N-cadherin, Snail and vimentin, evaluated by IB of total extracts from tumors of CC09 xenografts 


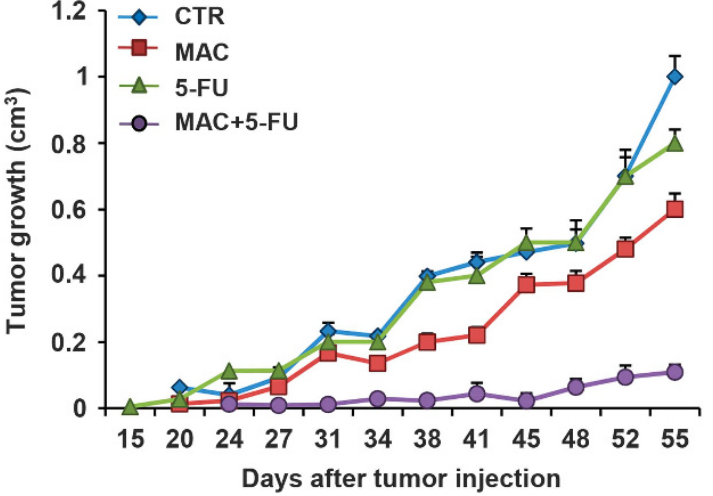

Figure 6 Macitentan inhibits tumor growth and restores sensitivity to 5-FU in CRC-SC xenografts. CC09 cells $\left(5 \times 10^{5}\right)$ were injected s.c. into the flank of nude mice. When tumors were detected, mice were treated with vehicle (CTR), or MAC (30 mg/Kg/oral daily), or 5-FU ( $15 \mathrm{mg} / \mathrm{Kg} / \mathrm{i}$.p daily), or MAC (30 mg/Kg/oral daily) with 5-FU (15 mg/Kg/i.p daily) combination for 4 weeks. The comparison of the time course of tumor growth curves by two-way ANOVA with group-by-time interaction for tumor growth was statistically significant $(P<0.05)$. Data points, averages \pm S.D.

and apoptosis induction. From a molecular standpoint, the hallmark of CRC-SC has been shown to be the abnormal activation of $\beta$-catenin signaling pathway and subsequent nuclear $\beta$-catenin accumulation. ${ }^{2,11-15} \beta$-catenin and ET-1R signaling pathways are critically involved in the progression of CRC. Our study discloses multi-point cross-talk between $\beta$-catenin and ET-1R/ $\beta$-arr1 pathway in CRC-SC, indicating a promising therapeutic strategy for CRC patients. We describe the mechanistic link between ET-1 and $\beta$-catenin through the specific interaction with $\beta$-arr1. Notably, $\beta$-arr1 acts as a transcription co-activator that forms a complex with $\beta$-catenin/ TCF and co-bind target genes, including ET-1. Indeed we reveal that, in response to ET-1R activation, $\beta$-arr1 could control two aspects of $\beta$-catenin nuclear functions: nuclear accumulation and assembly of a transcriptional complex. Consistent with a role of functional hub to organize nuclear complex, $\beta$-arr1 promotes the recruitment of $\mathrm{p} 300$ with TCF on ET-1 proximal promoter, and histone modification associated with ET-1 gene transcription. Macitentan interfered the functional interplay between $\beta$-catenin and $E T_{A} R / \beta$-arr1, suppressing the transactivation of TCF4 that is essential for target gene transcription. Therefore, based on our findings, we may hypothesize that ET-1R blockade might modulate the ET-1 signaling that controls the preferences of $\beta$-arr1 engagement, such as $\beta$-catenin, which can act to convey a persistent feedback protective ET-1 autocrine loop that sustains poor drug sensitivity, EMT and invasive features. ${ }^{47}$ Our data reinforce the notion that ET-1R is an important driver in CRC, ${ }^{17-29}$ indicating ET-1R as novel therapeutic targets for CRC. Interestingly, ET-1R blockade by macitentan may have a dual anti-ET-1R and anti- $\beta$-catenin activity that might be therapeutically explored. In this context, our results obtained in CRC preclinical models, indicated that macitentan, interfering with the epigenetic mechanism utilized by ET-1R/ $\beta$-arr1 to regulate $\beta$-catenin-driven signaling and survival pathways, significantly improves the efficacy of OX and 5-FU-based regimens, preventing the tumor growth and increasing the sensitivity of CRC-SC to the cytotoxic agents. Much of the plasticity associated with CRC-SC arises from the local niche, highlighting the regulatory effects of the tumor microenvironment. In this regard, the potential advantage of using the dual $E T_{A} R / E T_{B} R$ antagonist macitentan is to target not only $C R C$, which express mainly $\mathrm{ET}_{\mathrm{A}} \mathrm{R},{ }^{17-29}$ but also tumor-associated stromal elements, such as vascular, lymphatic and inflammatory cells and fibroblasts, which all express $E T_{B} R \cdot{ }^{16,31} E T_{B} R$ signaling is pro-angiogenic and may also impair antitumour immunity by preventing the maturation and function of dendritic cells, which are pivotal for the initiation of $\mathrm{T}$ cellmediated immune responses and the homing of $T$ cells to tumors. ${ }^{48,49}$ Therefore, the FDA approved small molecule macitentan, interfering with both $E T_{A} R$ and $E T_{B} R$, might offer a more efficacious therapeutic strategy in combination with clinical cytotoxic drugs, because it might target aggressive CRC-SC, disabling multiple signaling circuits activated by $\mathrm{ET}_{\mathrm{A}} \mathrm{R} / \beta$-arr1 axis and microenvironment-associated elements expressing $E T_{B} R$, offering also the opportunity to enhance antitumor immune response. ${ }^{50-53}$ Of note, the cancer genome atlas (TCGA) RNAseqv2 data show high mRNA levels of $\mathrm{ET}_{\mathrm{A}} \mathrm{R}$, as well as of $\beta$-catenin, in colon adenocarcinoma samples $(n=459)$ compared with normal colon tissues $(n=41)$, as displayed with FireBrowse. The mRNA expression of $\mathrm{ET}_{\mathrm{A}} \mathrm{R}$ and $\beta$-catenin was significantly upregulated in tumor samples compared with normal $(P=1.0554 \mathrm{e}-13$ and $P=7.3709$ e- 11 , respectively, as evaluated by Wilcoxon ranksum test). We propose that high expression levels of $E T_{A} R$ function in CRC, at least in part, through the connection of $\beta$-catenin pathway. The preclinical data demonstrating that the combined treatment of macitentan and OX or 5-FU effectively reduced tumor growth suggest that $\mathrm{CRC}$ patients with tumor that overexpress $E T_{A} R$ and $\beta$-catenin may benefit from this combination therapy. Therefore, targeting ET-1R, empowering the $\beta$-catenin/ET-1 circuit, can represent a necessary measure to reach clinical efficacy for combination therapy in CRC patients. Macitentan can represent an opportunity to block connections between signaling pathways that interfere with chemotherapy drug efficacy in CRC. Our demonstration of non-canonical cross-talk between $\beta$-catenin and ET-1R/ $\beta$-arr1 may have far-reaching implications in CRC and in other tumors in which ET-1R signaling is important. These data complement and add greater relevance to previous studies in ovarian, ${ }^{31,51-53}$ gliobastoma, ${ }^{50}$ as well as breast and lung cancer brain metastasis models, ${ }^{54}$ demonstrating that, regardless of the cancer type, ET-1R might represent a vulnerability node that should be blocked to enhance sensitivity to chemotherapy. Taken together, our study identified ET-1R/ $\beta$-arr1 as an important actionable node, demonstrating that ET-1R blockade by macitentan not only inhibits tumor growth of xenografts but also sensitizes these to chemotherapeutic agents, revealing a new prospective on the CRC patient treatment.

\section{Materials and Methods}

Materials. ET-1 was (Bachem, Bubendorf, Torrance, Switzerland) and it was used at $100 \mathrm{nM}$ and incubated with the cells for the indicated times. Macitentan (MAC), also N-(5-[4-bromophenyl]-6-\{2-[5-bromopyrimidin-2-yloxy]ethoxy\}pyrimidin-4-yl)-N'-propylsulfamide, (Actelion Pharmaceuticals, Allschwil, Switzerland). Pre-treatment of cells with MAC, was used at the concentration of $1 \mu \mathrm{M}$ for $30 \mathrm{~min}$ prior to the addition of ET-1. Oxaliplatin (SUN PHARMA, Goregaon (E), Mumbai) used at $100 \mu \mathrm{M}$ and Fluorouracil (5-FU) (TEVA, Petach Tikva, Israel), used at $50 \mu \mathrm{g} / \mathrm{ml}$. 
Cell culture. The patient-derived CRC-SC enriched cultures (CC09,CSC5, CSC2 and CSC1), isolated from human tumor samples and capable to reproduce a histological copy of the original patient tumor when inoculated in immunocompromised mice, were kindly provided by the Istituto Superiore di Sanità (ISS) CSC biobank. ${ }^{3,10,12}$ Cells were cultured in ultra-low attachment plates and maintained in stem cell medium (DMEM/F12, supplemented as reported in ref. 10) and monthly tested for mycoplasma contamination. Genomic analysis of CRC-SC showed that CC09 carried mutant BRAF, PIK3CA, APC, TP53 and SMAD4; CSC5 carried mutant KRAS, PIK3CA, APC and SMAD4; CSC2 carried mutant KRAS, APC, TP53 and SMAD4; CSC1carriedmutant PIK3CA, APC and SMAD4 (ref. 3) and unpublished results.

Immunoblotting analysis. Whole-cell lysates of CRC-SC were prepared using a ice-cold modified RIPA buffer $(50 \mathrm{mM}$ Tris- $\mathrm{HCl} \mathrm{pH} \mathrm{7.4,} 250 \mathrm{mMNaCl}, 1 \%$ Triton X-100, $1 \%$ sodium deoxycholate, $0.1 \%$ SDS) containing a mixture of protease and phosphatase inhibitors or NE-PER nuclear and cytoplasmic extraction reagents (Termo Fisher Scientific, Waltham, USA) to separate cytoplasmic and nuclear fractions. Protein content of the extracts was determined using protein assay kit (Bio-Rad, Hercules, CA, USA) and resolved by SDS-PAGE. Immunoblotting of Abs specific for $\beta$-arr1 (K-16: sc-9182), $\beta$-Catenin (E-5: sc-7963), tubulin (DM1A: SC32293), MMP-2 (K-20: sc-8835 ), MMP-9 (M-17: sc-6841), Snail (E-18: sc-10432), vimentin (C-20: Sc-7557), Histone H3 (C-16: sc-8654), PCNA (F-2: sc-25280), (Santa Cruz Biotechnology Dallas, TX, USA), HSP-70 (Enzo Life Sciences, New York, USA, ADI-SPA-812), Twist (ab50581), $\mathrm{ET}_{\mathrm{A}} \mathrm{R}$ (ab178454), $\mathrm{ET}_{\mathrm{B}} \mathrm{R}$ (ab39960) (Abcam, Cambridge, UK), AKT (9272) pAKT (Ser-473) (9271), p44/42MAPK (9102), pp42/44MAPK (4377), cleaved-PARP (9541), non-phospho (active) $\beta$ Catenin (Ser33/37/Thr41) (4270) (Cell Signaling, Beverly, MA, USA), N-cadherin (610920), E-cadherin (610181) (BD Biosciences, Franklin Lakes, NJ, USA) were detected using HRP-conjugated anti-mouse or anti-rabbit Abs (Pierce, 31460) and visualized by enhanced chemiluminescence detection system (ECL, Bio-Rad).

Immunoprecipitation analysis. Nuclear extracts were immunoprecipitated as previously described ${ }^{31}$ using $\beta$-arr1, or non-specific immunoglobulin $\mathrm{G}$ (IgG) (Santa Cruz Biotechnology) and protein G-agarose beads (Thermo Fisher Scientific) at $4^{\circ} \mathrm{C}$ overnight. Immunoprecipitates were resolved by SDS-PAGE and the proteins were detected by IB with the following Abs: $\beta$-Catenin, $\beta$-arr1 and Histone 3 (Santa Cruz Biotechnology). To obtain clean and specific IB signals of $\beta$-arr1 which run very close to heavy chain of $\mathrm{IgG}$, we used HRP-conjugated protein A (Thermo Scientific, Waltham, MA, USA) instead of HRP-conjugated secondary Ab.

RNA silencing and transfection. For the silencing of $\beta$-arr1, the CRC-SC were transiently transfected with ON-TARGET plus Human ARRB1 siRNA-SMART pool, containing four different siRNAs targeting $\beta$-arr1 (Dharmacon, Lafayette, CO, USA). The ON-TARGET plus Control Non-targeting siRNA (Dharmacon) was used as negative control. For exogenous expression of $\beta$-arr1 we used pcDNA3- $\beta$-arr1FLAG (wild-type) plasmid vector, containing a 'wobble' mutant construct encoding rat $\beta$-arr1 sequences resistant to small interfering RNA targeting, kindly provided by Dr. Robert Lefkowitz (Howard Hughes Medical Institute, Duke University, Durham, NC,USA). Cells transfected with the empty vector pcDNA3 were used as negative control (Mock).

RNA isolation and qPCR. Total RNA was isolated using Trizol (Thermo Fisher Scientific) according to the manufacturer's protocol. RNA was reversed transcribed using Super Script VILO cDNA synthesis kit (Thermo Fisher Scientific). Quantitative real-time PCR (qPCR) was performed by using LightCycler rapid thermal cycler system (Roche Diagnostics, Basel, Switzerland) and 7500 Fast realTime PCR System (Thermo Fisher Scientific). The expression levels of mRNA were determined by normalizing to cyclophilin-A mRNA expression. Each PCR analysis was done twice separately. Final data were obtained by using $2-\Delta \Delta \mathrm{Ct}$ method. The primers sets used were as follows: ET-1 F: CACCGAATTCGAATGTGAC and ET-1R: 5'-TCCTCTGCTGGTTCCTGACT-3'; $\quad \mathrm{ET}_{\mathrm{A}} \mathrm{R} \quad \mathrm{F}$ : 5'-GTCTGCTGTGGGCA ATAGTTG-3' and ET ${ }_{A} R$ R: 5'-GCTTCCTGGTTACCACTCATCAA-3'; ET R R: 5'TCCCGTTCAGAAGACAGCTT-3' and ET $\mathrm{B}_{\mathrm{B}} \mathrm{R}$ R: $5^{\prime}$-CAGAGGGCAAAGACAAGGAC -3'; $\beta$-arr1 $\mathrm{F}$ : 5'-CAGTATGCAGACATCTGCCTTT-3' and $\beta$-arr1 R: 5'-AGTTC GTGTCTTCGTGCT-3'; E-cadherin F: 5'-CCCACCACGTACAAGGGTC-3' and E-cadherin R: 5'-ATGCCATCGTTGTTCACTGGA-3'; N-cadherin F: 5'-GGTGGAG GAGAAGAAGACCAG-3' and N-cadherin R: 5'-GGCATCAGGCTCCACAGT-3'; Snail F: 5'-CACTATGCCGCGCTCTTTCC-3' and Snail R: 5'-GTCGTAGGGCTGC TGGAAG-3'; Axin 2 F: 5'-CTGGCTTTGGTGAACTGTTG-3' and Axin 2R: 5'-CTGG
CTTTGGTGAACTGTTG-3'; Cyclin D1 F: 5'-CTAATGGAATGGTTTGGGAATATCC ATGTA-3' and Cyclin D1 R: 5'-AAAGGAACTTATCATCCTGGCAAT-3'; Cyclophilin-A F: 5'-TTCATCTGCACTGCCAAGAC-3' and Cyclophilin-A R: 5'-TCGAGTTGTCCA CAGTCAGC-3'.

Chromatin immunoprecipitation. Chromatin was extracted from CRC-CS cells $\left(5 \times 10^{6}\right)$ and ChIP assays were performed as previously described. ${ }^{31}$ The differential binding between proteins and promoter DNA was examined by PCR. The primary Abs used were as follows: anti- $\beta$-catenin (E-5: sc-7963), anti- $\beta$-arr1(K-16: sc-9182), anti-p300 (N-15: sc-584), TCF4 (H-125: sc-13027) (Santa Cruz Biotechnology) anti-acetylated Histone H3 (Lys 27) (Millipore, Billerica, MA, USA, 07-360). The primers used were as follows: ET-1 promoter $5^{\prime}$-CAGCTTGCAA AGGGGAAGCG-3' and 5'-TCCGACTTTATTCCAGCCCC-3'.

Luciferase reporter gene assay. The CRC-SC were transiently transfected, using Lipofectamine 2000 (Thermo Fisher Scientific) according to manufacturer's instructions, with pGL3-SNA $(-869 /+59)$ construct (kindly provided by Dr. A. Garcia de Herreros, Institut Municipal d'Investigació Mèdica, Universitat Pompeu Fabra, Barcelona, Spain) or with pGL2-Ecad3 construct (kindly provided by Dr. E.R. Fearon, University of Michigan, Ann Arbor, MI, USA), respectively containing luciferase gene under the control of the human Snail and E-cadherin promoter, and with $\mathrm{pCMV}-\beta$-galactosidase vector (Promega, Madison, WI, USA). Transcriptional activity of $\beta$-catenin/TCF was evaluated by transient transfection of CRC-SC with TOP/Flash luciferase reporter, containing multiple TCF4 binding sites for $\beta$-catenin and FOP/Flash luciferase reporter (negative control) (results were expressed as the ratio of TOP/Flash over FOP/Flash activity) and PCMV- $\beta$ galactosidase vector. To measure the ET-1 promoter activity, the human CRC-SC, were transiently co-transfected with ET-1 promoter reporter sequence, spanning -1300 to +230 bp surrounding the transcriptional initiation site and containing a functional TBE located at -73 to $-67 \mathrm{bp}$, kindly provided by Dr. Z. Zhang (University of California San Diego School of Medicine, La Jolla, CA, USA), and pCMV- $\beta$ galactosidase vector. Reporter activity was measured using the Luciferase assay system (Promega) and normalized to $\beta$-galactosidase activity.

Gelatin zymography. To detect MMP-9 and -2 activity in conditioned media, CRC-SC transiently transfected with si- $\beta$-arr1 or with negative control, were stimulated with ET-1 or MAC, alone or in combination for $24 \mathrm{~h}$. Conditioned media was collected and concentrated by using Spin-X UF concentrator columns (Corning, New York, NY, USA ). Conditioned medium was separated by $9 \%$ SDS-PAGE gels containing $1 \mathrm{mg} / \mathrm{ml}$ gelatin. The gels were washed for $30 \mathrm{~min}$ at $22{ }^{\circ} \mathrm{C}$ in $2.5 \%$ Triton $\mathrm{X}-100$ and then incubated in $50 \mathrm{mM}$ Tris (pH 7.6), $1 \mathrm{mM} \mathrm{ZnCl}$, and $5 \mathrm{mM} \mathrm{CaCl} 2$ for $18 \mathrm{~h}$ at $37^{\circ} \mathrm{C}$. After incubation the gels were stained with $0.2 \%$ Coomassie Blue. Enzyme-digested regions were identified as white bands on a blue background and quantified by computerized image analysis of the band. Molecular sizes were determined from the mobility, using gelatin zymography standards (Bio-Rad Laboratories, Richmond, CA, USA).

Invasion assay. Chemoinvasion assays were carried out using modified Boyden Chambers consisting of transwell membrane filter inserts with $8 \mu \mathrm{m}$ size polycarbonate membrane precoated with polymerized collagen placed in a 24-well plate (BD Biosciences). The human CRC-SC clones transiently transfected with si- $\beta$-arr1 or with negative control, were stimulated with ET-1 or MAC, alone or in combination with ET-1, added to the lower chamber. The cells were left to migrate for $24 \mathrm{~h}$ at $37^{\circ} \mathrm{C}$. Cells on the upper part of the membrane were scraped using a cotton swab and the migrated cells were stained using Diff-Quick kit (Merz-Dade). The experiment was performed in triplicates for all conditions described. From every transwell, several images were taken under a phase-contrast microscope at $\times 10$ magnification and two broad fields were considered for quantification. The results of the analysis of the individual photos are depicted as dots in the various graphs, normalized to control and shown as fold of control.

ELISA. The release of ET-1 in media of CRC-SC was measured in triplicate on microtiter plates by using an ELISA kit (Phoenix Pharmaceuticals, Burlingame, CA, USA) according to the manufacturer's instructions.

Cell viability analysis. The human CRC-SC were seeded in triplicates, in 24-well plates. The cells were transiently transfected with si- $\beta$-arr1 or $\beta$-arr1-FLAG or with specific negative control and treated with ET-1, MAC, OX and 5-FU, alone or in combination. After 24 or 48 or $72 \mathrm{~h}$ cell viability was determinated by counting the 
cells, for each time point, using a Neubauer-counting chamber and a bright field miscroscope. The trypan blue dye exclusion method was used to evaluate the percentage of viable cells.

Clonogenic assay. The CRC-SC tumor spheres were mechanically dissociated and the resulting cells were seeded at low densities (1000 cells/ml) in 12-well low adhesion plates at $1 \mathrm{ml}$ per well, in stemness medium with or without ET-1 or MAC, alone or in combination. After 7 days of growth, the tumor spheres obtained were analyzed and quantified by a phase-contrast microscope at $\times 10$ magnification.

CRC-SC xenografts. Athymic $\left(\mathrm{nu}^{+} / \mathrm{nu}^{+}\right)$mice, 5- to 6-week of age (Charles River Laboratories, Milan, Italy), were subcutaneously injected with $5 \times 10^{5}$ viable CRC-SC, in $100 \mu \mathrm{l} \mathrm{PBS/Matrigel} \mathrm{(BD} \mathrm{Biosciences)} \mathrm{into} \mathrm{the} \mathrm{flank,} \mathrm{following} \mathrm{the}$ guidelines of the Italian Ministry of Health. For all the CRC-SC, xenografts were detectable within 2-6 weeks. Tumor xenografts were extracted, formalin-fixed, and paraffin-embedded. Haematoxylin-eosin-stained sections were subsequently evaluated by a pathologist in comparison with human tumors. For drug testing, $5 \times 10^{5}$ viable CRC-SC, in $100 \mu \mathrm{l}$ PBS/Matrigel, were subcutaneously injected into the flank of mice and were allowed to grow until they reached a detectable size. Drug treatments were started when tumors were detected, mice were randomized into different groups of 10 mice undergoing the following treatments for 4 weeks: (i) vehicle (control), (ii) macitentan ( $30 \mathrm{mg} / \mathrm{Kg} / \mathrm{oral}$ daily), (iii) OX ( $0.25 \mathrm{mg} / \mathrm{Kg} / \mathrm{i} . \mathrm{p}$. once a week) or 5-FU (15 mg/Kg/i.p daily), (iv) macitentan plus OX or 5-FU. Tumor volume was measured with caliper and the tumor growth curves were plotted. Tumor volume was calculated using the formula: $\pi / 6$ larger diameter $\times\left(\right.$ smaller diameter). ${ }^{2}$ At the end of experiments all mice were euthanized and tumors were harvested and preserved for further analysis.

Statistical analysis. Statistical analysis was performed using Student's $t$-test and Fisher's exact test to compare in vitro experiments. The time course of tumor growth was compared across the groups using two-way ANOVA, with group and time as variables. All statistical tests were carried out using SPSS software (SPSS 11, SPSS Inc. Chicago, IL, USA). A two-sided probability value of $<0.05$ was considered statistically significant. The Wilcoxon rank-sum test was used to analyze the gene expression obtained from TCGA of colon adenocarcinoma samples.

\section{Conflict of Interest}

The authors declare no conflict of interest.

Acknowledgements. We gratefully acknowledge Aldo Lupo for technical assistance and Maria Vincenza Sarcone for secretarial support. This work was supported by the Italian Association for Cancer Research (AIRC) (AIRC18382 to AB) and AIRC $5 \times 1000$ (9979 to RDM).

1. Walker AS, Johnson EK, Maykel JA, Stojadinovic A, Nissan A, Brucher B et al. Future directions for the early detection of colorectal cancer recurrence. J Cancer 2014; 5: 272-280.

2. Clevers H. Wnt/beta-catenin signaling in development and disease. Cell 2006; 127: 469-480.

3. De Angelis ML, Zeuner A, Policicchio E, Russo G, Bruselles A, Signore M et al. Cancer stem cell-based models of colorectal cancer reveal molecular determinants of therapy resistance. Stem Cell Transl Med 2016; 5: 511-523.

4. Zeuner A, Todaro M, Stassi G, De Maria R. Colorectal cancer stem cells: from the crypt to the clinic. Cell Stem Cell 2014; 15: 692-705.

5. Colak S, Medema JP. Cancer stem cells-important players in tumor therapy resistance. FEBS J 2014; 281: 4779-4791.

6. Kemper K, Grandela C, Medema JP. Molecular identification and targeting of colorectal cancer stem cells. Oncotarget 2010; 1: 387-395.

7. Todaro M, Francipane MG, Medema JP, Stassi G. Colon cancer stem cells: promise of targeted therapy. Gastroenterology 2010; 138: 2151-2162.

8. Vermeulen L, Sprick MR, Kemper K, Stassi G, Medema JP. Cancer stem cells: old concepts new insights. Cell Death Differ 2008; 15: 947-958.

9. Ricci-Vitiani L, Lombardi DG, Pilozzi E, Biffoni M, Todaro M, Peschle $C$ et al. Identification and expansion of human colon-cancer-initiating cells. Nature 2007; 445: 111-115

10. Todaro M, Alea MP, Di Stefano AB, Cammareri P, Vermeulen L, lovino F et al. Colon cancer stem cells dictate tumor growth and resist cell death by production of interleukin-4. Cell Stem Cell 2007; 1: 389-402.
11. Francescangeli F, Contavalli $P$, De Angelis L, Baiocchi M, Gambara G, Pagliuca A et al. Dynamic regulation of the cancer stem cell compartment by Cripto-1 in colorectal cancer. Cell Death Differ 2015; 22: 1700-1713.

12. Todaro M, Gaggianesi M, Catalano V, Benfante A, lovino F, Biffoni $M$ et al. CD44v6 is a marker of constitutive and reprogrammed cancer stem cells driving colon cancer metastasis. Cell Stem Cell 2014; 14: 342-356.

13. de Sousa EM, Vermeulen L, Richel D, Medema JP. Targeting Wnt signaling in colon cancer stem cells. Clin Cancer Res 2011; 17: 647-653.

14. Kanwar S, Yu Y, Nautiyal J, Patel B, Majumdar A. The Wnt/ $\beta$-atenin pathway regulates growth and maintenance of colonospheres. Mol Cancer 2010; 9: 212-225.

15. Clevers H, Loh KM, Nusse R. Stem cell signaling. An integral program for tissue renewal and regeneration: Wnt signaling and stem cell control. Science 2014; 346 : 1248012-1248019.

16. Rosanò L, Spinella F, Bagnato A. Endothelin 1 in cancer: biological implications and therapeutic opportunities. Nat Rev Cancer 2013; 13: 637-651.

17. Wang Z, Liu P, Zhou X, Wang T, Feng X, Sun YP et al. Endothelin promotes colorectal tumorigenesis by activating YAP/TAZ. Cancer Res 2017; 77: 2413-2423.

18. Liakou P, Tepetes K, Germenis A, Leventaki V, Atsaves V, Patsouris E et al. Expression patterns of endothelin-1 and its receptors in colorectal cancer. J Surg Oncol 2012; 105 : 643-649.

19. Arun C, London NJ, Hemingway DM. Prognostic significance of elevated endothelin-1 levels in patients with colorectal cancer. Int J Biol Markers 2004; 19: 32-37.

20. Nie S, Zhou J, Bai F, Jiang B, Chen J, Zhou J. Role of endothelin A receptor in colon cancer metastasis: in vitro and in vivo evidence. Mol Carcinog 2014; 53: E85-E91.

21. Hoosein MM, Dashwood MR, Dawas K, Ali HM, Grant K, Savage F et al. Altered endothelin receptor subtypes in colorectal cancer. Eur J Gastroenterol Hepatol 2007; 19: 775-782.

22. Ali H, Dashwood M, Dawas K, Loizidou M, Savage F, Taylor I. Endothelin Receptor expression in colorectal cancer. J Cardiovasc Pharmacol 2000; 36: S69-S71.

23. Ali H, Loizidou M, Dashwood M, Savage F, Sheard C, Taylor I. Stimulation of colorecta cancer cell line growth by ET-1 and its inhibition by ET(A) antagonists. Gut 2000; 47: 685-688.

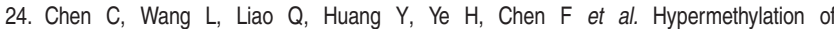
EDNRB promoter contributes to the risk of colorectal cancer. Diagn Pathol 2013; 10 : 199-205.

25. Asham E, Shankar A, Loizidou M, Fredericks S, Miller K, Boulos PB et al. Increased endothelin-1 in colorectal cancer and reduction of tumor growth by $\mathrm{ET}(\mathrm{A})$ receptor antagonism. Br J Cancer 2001; 85: 1759-1763.

26. Shankar A, Loizidou M, Aliex G, Fredericks S, Holt D, Boulos PB et al. Raised endothelin 1 levels in patient with colorectal liver metastases. Br J Surg 1998; 85: 502-506.

27. Kim TH, Xiong $\mathrm{H}$, Zhang $\mathrm{Z}$, Ren $\mathrm{B}$. beta-catenin activates the growth factor endothelin-1 in colon cancer cells. Oncogene 2005; 24: 597-604.

28. Puglisi MA, Barba M, Corbi M, Errico MF, Giorda E, Saulnier N et al. Identification of Endothelin-1 and NR4A2 as CD133-regulated genes in colon cancer cells. J Pathol 2011; 225: 305-314.

29. Haque SU, Dashwood MR, Heetun M, Shiwen X, Farooqui N, Ramesh B et al. Efficacy of the specific endothelin a receptor antagonist zibotentan (ZD4054) in colorectal cancer: a preclinical study. Mol Cancer Ther 2013; 12: 1556-1567.

30. Bhattacharya B, Low SH, Chong ML, Chia D, Koh KX, Sapari NS et al. Acquired resistance to combination treatment through loss of synergy with MEK and PI3K inhibitors in colorectal cancer. Oncotarget 2016; 7: 29187-29198.

31. Rosano L, Cianfrocca R, Tocci P, Spinella F, Di Castro V, Caparra V et al. Endothelin A receptor/ $\beta$-Arrestin signaling to the Wnt pathway renders ovarian cancer cells resistant to chemotherapy. Cancer Res 2014; 74: 7453-7464.

32. Rosano L, Cianfrocca R, Tocci P, Spinella F, Di Castro V, Spadaro F et al. $\beta$-arrestin- 1 is a nuclear transcriptional regulator of endothelin-1-induced $\beta$-catenin signalling. Oncogene 2013; 32: 5066-5077.

33. Rosanò L, Cianfrocca R, Spinella F, Di Castro V, Nicotra MR, Lucidi A et al. Acquisition of chemoresistance and EMT phenotype is linked with activation of the endothelin A recepto pathway in ovarian carcinoma cells. Clin Cancer Res 2011; 17: 2350-2360.

34. Rosano $L$, Bagnato $A$. Convergent pathways link the endothelin $A$ receptor to the betacatenin: the beta-arrestin connection. Cell Cycle 2009; 8: 1462-1463.

35. Rosanò L, Cianfrocca R, Masi S, Spinella F, Di Castro V, Biroccio A et al. Beta-arrestin links endothelin $A$ receptor to beta-catenin signaling to induce ovarian cancer cell invasion and metastasis. Proc Natl Acad Sci 2009; 106: 2806-2811.

36. Soh B, Ng SY, Wu H, Buac K, Park JH, Lian X et al. Endothelin-1 supports clonal derivation and expansion of cardiovascular progenitors derived from human embryonic stem cells. Nat Commun 2016; 7: 10774.

37. Zhan Y, Xu C, Liu Z, Yang Y, Tan S, Yang Y et al. $\beta$-Arrestin1 inhibits chemotherapy-induced intestinal stem cell apoptosis and mucositis. Cell Death Dis 2016; 7: e2229.

38. Bagnato A, Salani D, Di Castro V, Wu-Wong JR, Tecce R, Nicotra MR et al. Expression of endothelin 1 and endothelin A receptor in ovarian carcinoma: evidence for an autocrine role in tumor growth. Cancer Res 1999; 59: 720-727.

39. Pereira L, Mariadason JM, Hannan RD, Dhillon AS. Implications of epithelial-mesenchymal plasticity for heterogeneity in colorectal cancer. Front Oncol 2015; 5: 13 eCollection 2015.

40. Han XY, Wei B, Fang JF, Zhang S, Zhang FC, Zhang HB et al. Epithelial-mesenchymal transition associates with maintenance of stemness in spheroid-derived stem-like colon cancer cells. PLoS One 2013; 8: e73341. 
41. Li J, Zhou BP. Activation of $\beta$-catenin and Akt pathways by Twist are critical for the maintenance of EMT associated cancer stem cell-like characters. BMC Cancer 2011; $11: 49$.

42. Polyak K, Weinberg RA. Transitions between epithelial and mesenchymal states: acquisition of malignant and stem cell traits. Nat Rev Cancer 2009; 9: 265-273.

43. Mani SA, Guo W, Liao MJ, Eaton EN, Ayyanan A, Zhou AY et al. The epithelial-mesenchymal transition generates cells with properties of stem cells. Cell 2008; 133: 704-715.

44. Brabletz T, Hlubek F, Spaderna S, Schmalhofer O, Hiendlmeyer E, Jung A et al. Invasion and metastasis in colorectal cancer: epithelial-mesenchymal transition, mesenchymal-epithelial transition, stem cells and beta-catenin. Cells Tissues Organs 2005; 179: 56-65.

45. Wang YK1, Zhu YL, Qiu FM, Zhang T, Chen ZG, Zheng S et al. Activation of Akt and MAPK pathways enhances the tumorigenicity of $\mathrm{CD} 133+$ primary colon cancer cells. Carcinogenesis 2010; 31: 1376-1380.

46. Catalano V, Dentice M, Ambrosio R, Luongo C, Carollo R, Benfante A et al. Activated thyroid hormone promotes differentiation and chemotherapeutic sensitization of colorectal cancer stem cells by regulating Wnt and BMP4 signaling. Cancer Res 2016; 76: 1237-1244.

47. Rosanò L, Bagnato A. $\beta$-arrestin1 at the cross-road of endothelin- 1 signaling in cancer. J Exp Clin Cancer Res 2016; 35: 121-132.

48. Buckanovich RJ, Facciabene A, Kim S, Benencia F, Sasaroli D, Balint K et al. Endothelin B receptor mediates the endothelial barrier to $T$ cell homing to tumors and disables immune therapy. Nat Med 2008; 14: 28-36.

49. Kandalaft LE, Facciabene A, Buckanovich RJ, Coukos G. Endothelin B receptor, a new target in cancer immune therapy. Clin Cancer Res 2009; 15: 4521-4528.

50. Kim SJ, Lee HJ, Kim MS, Choi HJ, He J, Wu Q et al. Macitentan, a dual endothelin receptor antagonist, in combination with temozolomide leads to glioblastoma regression and long-term survival in mice. Clin Cancer Res 2015; 21: 4630-4641.
51. Coffman L, Mooney C, Lim J, Bai S, Silva I, Gong Y et al. Endothelin receptor-A is required for the recruitment of antitumor $T$ cells and modulates chemotherapy induction of cancer stem cells. Cancer Biol Ther 2013; 14: 184-192.

52. Kim SJ, Kim JS, Kim SW, Yun SJ, He J, Brantley E et al. Antivascular therapy for multidrug-resistant ovarian tumors by macitentan, a dual endothelin receptor antagonist. Transl Oncol 2012; 5: 39-47.

53. Kim SJ, Kim JS, Kim SW, Brantley E, Yun SJ, He J et al. Macitentan (ACT-064992), a tissue-targeting endothelin receptor antagonist, enhances therapeutic efficacy of Paclitaxel by modulating survival pathways in orthotopic models of metastatic human ovarian cancer. Neoplasia 2011; 13: 167-179.

54. Lee HJ, Hanibuchi M, Kim SJ, Yu H, Kim MS, He J et al. Treatment of experimental human breast cancer and lung cancer brain metastases in mice by macitentan, a dual antagonist of endothelin receptors, combined with paclitaxel. Neuro Oncol 2016; 18: 486-496.

(c) (1) $\odot \odot$ This work is licensed under a Creative Commons c) Attribution-NonCommercial-NoDerivs 4.0 International License. The images or other third party material in this article are included in the article's Creative Commons license, unless indicated otherwise in the credit line; if the material is not included under the Creative Commons license, users will need to obtain permission from the license holder to reproduce the material. To view a copy of this license, visit http://creativecommons.org/licenses/by-nc-nd/4.0/

(C) The Author(s) 2017

Supplementary Information accompanies this paper on Cell Death and Differentiation website (http://www.nature.com/cdd) 